\section{Extraction and identification of microplastics from mussels: Method development and preliminary results}

\author{
Raffaelina Mercogliano, \\ Serena Santonicola, ${ }^{2}$ Gennaro Raimo, ${ }^{2}$ \\ Maurizio Gasperi, ${ }^{2}$ \\ Giampaolo Colavita ${ }^{2}$
}

${ }^{1}$ Department of Veterinary Medicine and Animal Production, University of Naples; ${ }^{2}$ Department of Medicine and Health Sciences, University of Molise, Campobasso, Italy

\begin{abstract}
Microplastics (MPs) are an emerging threat to marine ecosystems. One of the primary environmental risks is their bioavailability for aquatic organisms. Some fish and bivalves are of particular interest because their feeding strategies expose them to particles present in the water column. The aim of the study was to assess an extraction method in order to isolate and quantify MPs from fish gastrointestinal tract (n.8) and muscle (n.4), and bivalves (n.8) samples. The accuracy of the method was assessed through the calculation of the recovery percentage in samples spiked with a known number of MPs using microscopic observation. Successively, the extraction was preliminarily applied on n.20 mussels collected from mariculture plants of the Tyrrhenian and the Adriatic Sea. The results of the digestion protocol showed an average extraction yield of $80 \%$ in fish gastrointestinal tracts, $90 \%$ in fish muscle samples, and $95 \%$ in mussels. Preliminary analysis carried out on farmed mussels showed an average abundance of 3.8 items/individual, and 0.5 items/g of tissue, among those black, was the most represented color.
\end{abstract}

\section{Introduction}

Microplastics (MPs) as fibers, fragments, spheroids, beads, granules, pellets, or flakes with a grain size of 0.1-5000 $\mu \mathrm{m}$, may result directly from human activity (primary MPs) or the fragmentation of larger plastic objects (secondary MPs) by mechanical, biodegradation, and photodegradation in the aquatic ecosystem. The majority of MPs present in seafood are composed by polyvinyl chloride (PVC, plastic coatings for the freight transport and bottle tops), polyethylene (PE, fishing gear), polyethylene terephthalate (PET, water bottles), polypropylene (PP, from the fragmentation of soft plastic bags, and food packaging film) (Avio et al., 2015; EFSA, 2016; Mercogliano et al., 2020).

When ingested by marine organisms, MPs may be transferred from one trophic level to the next of the marine web, leading to direct physical damage and potential toxicity effects. In addition, they may leach plastic additives, including persistent organic pollutants and potentially toxic chemicals adsorbed at higher concentrations than those found in the surrounding environment. Pollutants may be transferred and accumulate in different tissues of organisms, undergoing biomagnification along the food chain (Barboza et al., 2018; Mercogliano et al., 2020).

Global contamination of the marine environment by plastic has led to the discovery of MPs in a range of marine species, including those for human consumption ( $\mathrm{Li}$ et al., 2019). Commercial fish and seafood represent one of the most important routes of human exposure through the diet (Silva et al., 2018). The assessment of the occurrence of MPs in marine biota and their trophic transfer is based on plastic isolation and identification. Methods for characterizing MPs include several steps as visual identification followed by chemical identification of plastic polymers (Lusher et al., 2017; Bessa et al., 2019). Visual identification is allowed after extraction, clean-up, isolation (or separation) of particles from biological tissues. The extraction of MPs from the whole organism or their tissues and the chemical digestion are crucial steps (Foekema et al. 2013; Lusher, 2015). The percentage of MPs that the method is capable of extracting from the samples is defined as recovery efficiency and represents the accuracy of the method. Conventionally, visual sorting with the naked eye is used to identify MPs in the 1-5 mm size range, like colorful plastic fragments and pre-production resin pellets. Stereo- microscopy may be associated to identify size falls in the hundreds of micron range, and ambiguous plastic-like particles based on data on surface texture and structure of particles. Analysis with energy-dispersive X-ray spectroscopy (EDS) may be also used to provide data on the MP composition and to identify carbondominant plastics from inorganic particles, while Scanning electron microscopy (SEM) can provide clear and high-magnification images of plastic-like particles, but it is unable to identify the color of plastic particles (Shim et al., 2018). Therefore, the chemical characterization of polymer defines the composition of the extracted MPs and may be carried out through Fourier
Correspondence: Serena Santonicola, Department of Medicine and Health Sciences, University of Molise

Via Francesco De Sanctis, 1, 86100 Campobasso, Italy.

Tel.: +39.0874.404877 - Fax: +39.0874.418373.

E-mail: serena.santonicola@unimol.it

Key words: Microplastics, Digestion method, Engraulis encrasiculos, Mytilus galloprovincialis.

Acknowledgments: The authors would like to thank Prof. Francesco Regoli and Dr. Carlo Giacomo Avio from DISVA, Polytechnic University of Marche, for their advice in the analytical activity performed.

Contributions: The authors contributed equally.

Conflict of interest: The authors declare no potential conflict of interest.

Funding: This study was supported by the Project "SIstemi di Rilevamento dell'Inquinamento MArino da Plastiche e successivo recupero-riciclo. SIRIMAP PON project" from the Ministry for University and Research (MIUR), Italy.

Availability of data and materials: All data and materials are available by authors.

Received for publication: 17 July 2020.

Revision received: 1 February 2021.

Accepted for publication: 1 February 2021.

This work is licensed under a Creative Commons Attribution-NonCommercial 4.0 International License (CC BY-NC 4.0).

CCopyright: the Author(s), 2021

Licensee PAGEPress, Italy

Italian Journal of Food Safety 2021; 10:9264

doi:10.4081/ijfs. 2021.9264

transform infrared (FTIR) spectroscopy, Raman spectroscopy, or thermo-analytical techniques (Catarino et al., 2017).

In marine organisms of commercial interest, the ingestion is considered as the main way to uptake MPs. The feeding strategies may influence the MP levels, the type, and the distribution along the marine food chain. Engraulis encrasicolus is one of the most selective feeder fish of the Tyrrhenian and the Adriatic Sea, which may ingest small planktonic organisms and also floating MPs (Mercogliano et al., 2020). Bivalves such as Mytilus galloprovincialis are of particular interest because their extensive filter-feeding activity exposes them directly to MPs present in the environment. Accumulation and retention of MPs have been observed in mussels tissues and organs including foot and mantle. The 
ingested particles may be transferred towards the marine trophic web when mussels are predated by different marine species (i.e. carnivorous gastropods, sea breams, starfish) (Kolandhasamy et al., 2018). Mussels are also one of the most important vectors to transfer MPs into the human food chain (Li et al., 2016). Therefore, these species may be considered as particularly good candidates for the assessment of human exposure to MPs, being often consumed whole, and as indicators for chemical pollution monitoring worldwide (Digka et al., 2018; Renzi et al., 2018). However, the lack of harmonized monitoring protocols and laboratory procedures for MP analysis makes difficult the comparison of disposable data on the occurrence of plastics in marine biota and the risk assessment for human health (Lusher et al., 2017; Bessa et al., 2019).

The aim of the study was to describe a method for the extraction and quantification of MPs in seafood. The accurancy of the method was evaluated through the microscopic enumeration of MPs in spiked gastrointestinal (GI) and muscle samples of $E$. encrasiculos and spiked soft tissues of $M$. galloprovincialis after the digestion procedure. Then, the validated method was applied on $M$. galloprovincialis collected from mariculture plants of Tyrrhenian and the Adriatic Sea.

\section{Materials and Methods}

\section{Materials}

Sodium Chloride, Hydrogen Peroxide solution $30 \%$, and Potassium hydroxide were provided by Carlo Erba (Val De Reuil, France). Cellulose nitrate filters (pore size 8 $\mu \mathrm{m}$ ) and cellulose acetate filter (pore size $0.45 \mu \mathrm{m}$ ) were purchased from Sartorius Stedim Biotech (Gottingen, Germany). The filtrating system was provided by Advantec (Dublin, CA 94568, USA).

As contamination precaution, all of the liquid (freshwater, saltwater, and hydrogen peroxide) was filtered with $0.45 \mu \mathrm{m}$ cellulose acetate filter before use. All containers and beakers were rinsed three times with filter water before use to avoid contamination. Samples were covered by foil paper during digestion and when not in use. Filters were covered with glass lids during observation under a stereomicroscope (Zeiss $47 \quad 50 \quad 22$ West Germany Microscope).

\section{Sample collection}

In the first step, an extraction protocol was applied on E. encrasiculos and M. gal- loprovincialis samples collected. A blank extraction group without tissue was performed simultaneously to correct the potential procedural contamination.

GI tract (n.8 units) and muscle (n.4 units) of anchovies and all soft tissues of mussels (n.8 units) samples were spiked with a specific number (4-5 particles/sample) of virgin plastic particles (PA, PE, and PP) with different density characteristics. In brief, after the dissection, fish GI tract and muscle, and mussel samples were placed on a Petri dish, and a known number of particles was added to each sample using tweezers under microscopy observation. The samples were then put in a glass jar for the digestion procedure. The number of particles detected after applying the extraction procedure was used to calculate the recovery percentage of MPs, which was used to determine the ability of the digestion method to isolate MPs in unknown samples.

In the second step, n.20 samples of $M$. galloprovincialis (n.5 from Adriatic Coast; n.5 from Olbia, North-East Sardinia; and n.10 from the Gulf of Naples, Tyrrhenian Sea) were collected and analyzed.

\section{Extraction method development}

At the time of analysis, the GI tracts of E. encrasiculos were removed from the esophagus to the anal sphincter. M. galloprovincialis were washed with filtered water to remove associated debris and then a small knife was inserted between the two valves on the dorsal side, cutting the anterior adductor muscle, to open the valves.

According to Foekema et al. (2013) and Avio et al. (2015), the sample processing was performed based on a digestion method to degrade organic matter and enable detection of MP particles from fish and mussel tissues. In addition, some modifications were applied.

The obtained samples were filled with a $10 \% \mathrm{KOH}$ solution. The amount of $\mathrm{KOH}$ solution added was at least 3 times the volume of the biological material. The jars were stored overnight at $50^{\circ} \mathrm{C}$ in an oven until the dissolution of the organic material was observed to be complete.

After the digestion, each sample was added to $250 \mathrm{ml} \mathrm{NaCl}$ prefiltered hypersaline solution $\left(1.2 \mathrm{~g} / \mathrm{cm}^{3}\right)$, stirred, and decanted for $10 \mathrm{~min}$. The overlying water was directly filtered over a pore size of 8 $\mu \mathrm{m}, 47 \mathrm{~mm}$ diameter cellulose nitrate membrane filter using a filtrating system, consisting of filtration glass set, vacuum pump, manifold, and funnel. Glassware was accurately rinsed to increase the recovery efficiency of litter. The filtration step was carried out twice in order to obtain a better extraction performance. Then membranes with retained materials were transferred in a Petri dish with a $15 \% \mathrm{H}_{2} \mathrm{O}_{2}$ solution for the partial digestion of residual organic matter and allowed to dry in oven $\left(50^{\circ} \mathrm{C}\right.$, overnight), before the microscopical observation. For the accuracy of the method, the recovery rate (\%) of MPs was evaluated observing the dried filters obtained from the spiked samples under a stereomicroscope. The particles were counted and the recovery rate was expressed as the number of MPs counted divided by the number of MPs spiked into the mussel sample.

\section{Sample collection of commercial $M$. galloprovincialis}

According to Renzi et al. (2018) collected animals were measured to determine biometrics (maximum length, mm; weight, g). A representative number of mussels animals were collected from each tested stock selecting them from the same size class and preferring more represented size classes. Animals from the same size class (n.5 from Adriatic Coast; n.5 from Olbia, North-East Sardinia; and n.10 from the Gulf of Naples, Tyrrhenian Sea) were analyzed individually, dissected to open valves and weighted. Bivalves' length ranged within 5.5-8.7 cm. Stocks coming from the Adriatic coast and Gulf of Naples are similar and range respectively within $5.5-7.0 \mathrm{~cm}$ and $5.5-6.5 \mathrm{~cm}$. Specimens from Olbia are larger and they range within 6.3-8.7. The mean bivalves' weight was $9.752 \mathrm{~g}$ for mussels from Olbia, and 6.816 and $5.307 \mathrm{~g}$ for samples from the Adriatic Coast and Gulf of Naples, respectively.

\section{Extraction of microplastic from commercial M. galloprovincialis}

Before the application of the digestive method, whole mussels were stored at $-20^{\circ} \mathrm{C}$. At the time of analyses, the samples were subjected to the extraction method described before.

The filters were examined under the stereomicroscope for items resembling MPs. A visual assessment was applied to identify the morphotypes of MPs. The observed particles were counted and classified by color. In mussel samples particles abundance was expressed as:

a) average number of particles per individual in all individuals examined;

b) the average number of particles per individual in individuals containing fragments;

c) the average number of particles per gram of mussel tissue in individuals containing fragments.

According to Avio et al., 2015, textile fibers were found only occasionally and were excluded from the analysis because they could represent airborne contamination 
from clothing during the sampling or processing.

\section{Results}

The digestion method applied on $E$. engraulicos and M. galloprovincialis samples showed an average extraction yield of $88 \%$, with the recovery of $80 \%$ in fish GI, $90 \%$ in fish muscle samples, and $95 \%$ in mussel tissues (Table 1). Under microscope observation, the characteristcs of the spiked particles remained intact after the application of the extraction procedure, including the color (yellow for PA, white for PP, and green for $\mathrm{PE}$ particles). In particular, MP recovery was $95 \%$ for $\mathrm{PP}, 86 \%$ for $\mathrm{PE}$, and $80 \%$ for PA.

Preliminary results on the analyzed $n$. 20 farmed M. galloprovincialis showed an average number of 3.8 items/individual and 0.5 fragments/gram of the analyzed samples. In musses from the Gulf of Naples, the average number of fragments per individual is 4.7, while in those from Olbia and Adriatic Coast was 3.4 and 2.4, respectively. Black is the most represented color in all tested stocks (Table 2).

\section{Discussion}

The feeding strategy of marine organisms plays an important role in the amounts of ingested MPs. Filter feeding organisms, as M. galloprovincialis, can take up higher amounts of MPs than deposit feeders (Setälä et al., 2016; Mizraji et al., 2017). Pelagic fish, as E. Encrasiculos, may ingest a high number of MPs with higher frequency than demersal fish (Rummel et al., 2016; Güven et al., 2017). According to literature, anchovies may filter planktonic organisms only when they encounter an adequate patch of prey or when it is energetically convenient to switch from biting on single prey to indiscriminate filtering (Borme et al., 2009).

In the current study, these species were selected to assess the extraction protocol, since E. encrasiculos and M. galloprovincialis reflect MP contamination in pelagic habitats and the coastal water column, respectively (Mercogliano et al., 2020). MPs in fish are mostly detected in the stomach and intestine usually removed before the consumption, reducing consumer exposure. This is not the case of MPs in mussels soft tissues. Also anchovies may be consumed whole, and the digestive tract may be eaten leading to human exposure similarly to bivalves (EFSA, 2016; Digka et al.,
2018). However, MPs were also detected in the eviscerated flesh (whole fish excluding the viscera and gills) of commonly consumed dried fish species, evidencing that the evisceration does not necessarily eliminate the risk of MPs intake by humans (Karami et al., 2017).

The tested method revealed a good efficiency with an average extraction yield of $88 \%$, with the highest recovery percentage in M. galloprovincialis in E. encrasiculos muscle samples. In the present study, at least n.4/5 particles were recovered from the analyzed samples. Only in two samples of E. encrasiculos GI tract, recoveries were of $3 / 5$ particles. Other advantages of the applied digestive method were simplicity, uniformity in reporting results, and the possibility to minimize the time of analysis and associated errors. The applied alkaline digestion with $\mathrm{KOH}$ solution is effective for hydrolyzing complex biological matrices such as animal tissue and organs. A comparison of basic and acid digestion processes shows that alkaline digestion can be used with a greater range of polymers and present a lower risk of chemically modifying or structurally damaging particulates (Toussaint et al., 2019). Also the application of $\mathrm{H}_{2} \mathrm{O}_{2}$ solution on the filters helps to remove any residual biological tissues (Avio et al., 2015).

The tested protocol of extraction showed MP recovery of $95 \%$ for PP, $86 \%$ for $\mathrm{PE}$, and $80 \%$ for PA. It is possible that the different recovery rate might be probably due to the different polymer densities (Bessa et al., 2019). In fact, these polymers with different density and floating capacity along the water column, are among the most used and widespread in the environment. New biodegradable films have been synthesized for food packaging (Santonicola et al., 2017). Nevertheless, most food packaging materials made of plastics with a carboncarbon backbone structure as polymers are still used. Such polymers have a high potential to observe significant loading in the environment (Gomiero et al., 2019). Moreover, among the different factors influencing the marine pollution, plastic lines used in the farms may influence the MP abundance in farmed mussels (Mathalon and Hill, 2014).

The study was then applied to determine the occurrence of MPs in M. galloprovincialis samples from Tyrrhenian and the Adriatic Sea. Several studies showed a

Table 1. Microplastic recovery using the digestion method on fish and mussel sample units.

\begin{tabular}{|c|c|c|c|}
\hline Sample & Spiked Mps (N.) & Recovered Mps (N.) & $\mathbf{R} \%$ \\
\hline \multicolumn{4}{|c|}{ Fish GI tract } \\
\hline $\mathrm{Gl}$ & 5 & 5 & 80 \\
\hline G2 & 5 & 4 & \\
\hline G3 & 5 & 3 & \\
\hline G4 & 5 & 4 & \\
\hline G5 & 5 & 5 & \\
\hline G6 & 5 & 4 & \\
\hline $\mathrm{G} 7$ & 5 & 4 & \\
\hline G8 & 5 & 3 & \\
\hline \multicolumn{4}{|c|}{ Fish Muscle } \\
\hline $\mathrm{F} 1$ & 5 & 4 & 90 \\
\hline F2 & 5 & 5 & \\
\hline F3 & 5 & 4 & \\
\hline F4 & 5 & 5 & \\
\hline \multicolumn{4}{|c|}{ Mussels Tissues } \\
\hline M1 & 5 & 4 & 95 \\
\hline M2 & 5 & 5 & \\
\hline M3 & 5 & 5 & \\
\hline M4 & 5 & 4 & \\
\hline M5 & 5 & 5 & \\
\hline M6 & 5 & 5 & \\
\hline M7 & 5 & 5 & \\
\hline M8 & 5 & 5 & \\
\hline Total & 100 & 88 & 88 \\
\hline
\end{tabular}


Table 2. Microplastics detected in commercial mussels.

\begin{tabular}{|c|c|c|c|c|c|}
\hline M. galloprovincialis & Origin & Lenght (cm) & Weight (g) & Fragments (n. and color) & Total \\
\hline S1 & Olbia, Italy & 6.3 & 5.52 & 1 green, 1 orange & 2 \\
\hline S2 & Olbia, Italy & 7.5 & 8.26 & 2 orange, 1 red & 3 \\
\hline S3 & Olbia, Italy & 8.7 & 14.01 & 5 orange, 3 black & 8 \\
\hline S4 & Olbia, Italy & 8.7 & 12.89 & 1 yellow, 2 colorless & 3 \\
\hline S5 & Olbia, Italy & 7.6 & 10.08 & 1 red & 1 \\
\hline S6 & Adriatc coast, Italy & 7 & 8,59 & 2 black, 2 colorless & 4 \\
\hline S7 & Adriatc coast, Italy & 6,5 & 6,86 & 1 black & 1 \\
\hline S8 & Adriatc coast, Italy & 5,5 & 3,68 & 1 pink & 1 \\
\hline S9 & Adriatc coast, Italy & 7 & 8,38 & 2 black & 2 \\
\hline S10 & Adriatc coast, Italy & 7 & 6,57 & 4 black & 4 \\
\hline S11 & Gulf of Naples, Italy & 6,3 & 4,54 & 1 blue, 1 red, 1 black & 3 \\
\hline S12 & Gulf of Naples, Italy & 6,5 & 5,47 & 9 black & 9 \\
\hline $\mathrm{S} 13$ & Gulf of Naples, Italy & 6 & 5,19 & 5 black, 1 colorless & 6 \\
\hline S14 & Gulf of Naples, Italy & 5,5 & 4,58 & 1 orange, 5 black, 1 grey & 7 \\
\hline S15 & Gulf of Naples, Italy & 5,5 & 4,29 & 3 black, 3 colorless & 6 \\
\hline S16 & Gulf of Naples, Italy & 6,5 & 5,66 & 3 colorless & 3 \\
\hline S17 & Gulf of Naples, Italy & 7 & 5,12 & 2 black & 2 \\
\hline S18 & Gulf of Naples, Italy & 6 & 6,11 & 1 black, 2 colorless & 3 \\
\hline S19 & Gulf of Naples, Italy & 6 & 5,75 & 1 black, 1 red & 2 \\
\hline S20 & Gulf of Naples, Italy & 6 & 6,36 & 3 black, 3 colorless & 6 \\
\hline Mean & & 6.64 & 6.92 & & 76 \\
\hline
\end{tabular}

strong positive linear relationship between MP levels in the water and the mussels. As filter feeders, they have a high capacity of MP ingestion with the prevalence of small size items $(<1 \mathrm{~mm})$ (Setälä et al., 2016; Digka et al., 2018; Phuong et al., 2018).

In our study, the highest numbers of items were detected in the samples S12 (n.9 particles) from the Gulf of Naples and S3 (n.8 particles) from Olbia with the prevalence of black and orange particles, respectively. The average number of MPs detected in bivalves (from 0.2-4.0 items/g) (EFSA, 2016) agrees with our study $(0.5$ items $/ g)$. MPs were found in M. galloprovincialis ranging from 1.5 to 7.6 and from 0.77 to 8.22 items/individual from coastal waters of China (Li et al., 2016; Qu et al., 2018) and 1.1 to 6.4 items/individual in all individuals from coastal waters of UK (Li et al., 2018). The results agree with literature and suggest that different distribution of MPs in mussels might be related to the contamination levels of the marine areas of origin, where intensive anthropic activities might influence the pollution. Mussels are considered good bioindicators of MPs in coastal areas and a positive linear correlation was observed between the abundance of MPs in the surrounding water and their tissues (Digka et al., 2018). According to literature, prelimi- nary results on the occurrence of MPs in $M$. galloprovincialis suggested widespread contamination in analyzed mariculture sites of coastal areas of the Tyrrhenian and the Adriatic Sea. Anthropogenic activities such as fisheries, aquaculture, shipping, and tourism are the primary source of litter contamination of the Mediterranean Sea (Digka et al., 2018). The MP levels detected in the supermarket bought mussels from mariculture sites represent a route for human exposure and their quantification should be included as food safety management measures (Li et al., 2019).

\section{Conclusions}

In the European Union, marine litter is addressed by one of the 11 Descriptors to achieve a Good Environmental Status set by the Marine Strategy Framework Directive $2008 / 56 /$ EC. Because of the absence of standard methods and harmonized laboratory procedures for MP analysis, the comparison of disposable data on the occurrence of plastics in marine biota and the risk assessment for human health remain difficult. To support this issue, this study presented an efficient protocol for the extraction and quantification of MPs from the digestive tract and muscle of pelagic fish and soft tissues of mussels, and relative recovery efficiency. This protocol might be helpful to estimate the occurrence of MPs in commercial seafood. Preliminary results on M. galloprovincialis from different mariculture sites confirmed the wide distribution of MPs in the Thyrrhenian and the Adriatic Sea. The extracted particles will be analyzed through FTIR spectroscopy for chemical characterization of polymer composition and further analysis will be carried out on a significant number of mussels from different mariculture sites to provide data to assess human exposure to MPs.

\section{References}

Avio CG, Gorbi S, Regoli F, 2015. Experimental development of a new protocol for extraction and characterization of microplastics in fish tissues: first observations in commercial species from Adriatic Sea. Mar Environ Res 111:18-26.

Barboza LGA, Vethaak AD, Lavorante BR, Lundebye AK, Guilhermino L, 2018. Marine microplastic debris: An emerg- 
ing issue for food security, food safety and human health. Mar Pollut Bull 133:336-348.

Bessa F, Frias J, Kögel T, Lusher A, Andrade JM, Antunes J, Pedrotti ML, 2019. Harmonized protocol for monitoring microplastics in biota. Deliverable 4.3.

Borme D, Tirelli V, Brandt SB, Umani SF, Arneri, E, 2009. Diet of Engraulis encrasicolus in the northern Adriatic Sea (Mediterranean): ontogenetic changes and feeding selectivity. Mar Ecol Prog Ser 392:193-209.

Catarino AI, Thompson R, Sanderson W, Henry TB, 2017. Development and optimization of a standard method for extraction of microplastics in mussels by enzyme digestion of soft tissues. Environ Toxicol Chem 36:947-951.

Digka N, Tsangaris C, Torre M, Anastasopoulou A, Zeri C., 2018. Microplastics in mussels and fish from the Northern Ionian Sea. Mar Pollut Bull 135:30-40.

EFSA Panel on Contaminants in the Food Chain (CONTAM), 2016. Presence of microplastics and nanoplastics in food, with particular focus on seafood. Efsa $\mathrm{J}$ 14:e04501.

Foekema EM, De Gruijter C, Mergia MT, van Franeker JA, Murk AJ, Koelmans AA, 2013. Plastic in north sea fish. Environ Sci Technol 47:8818-24.

Gomiero A, Øysæd KB, Agustsson T, van Hoytema N, van Thiel T, Grati F, 2019. First record of characterization, concentration and distribution of microplastics in coastal sediments of an urban fjord in south west Norway using a thermal degradation method. Chemosphere 227:705-14.

Güven O, Gökdağ K, Jovanović B, Kıdeyş AE, 2017. Microplastic litter composition of the Turkish territorial waters of the Mediterranean Sea, and its occurrence in the gastrointestinal tract of fish. Environ Pollut 223:286-94.

Karami A, Golieskardi A, Ho YB, Larat V,
Salamatinia B, 2017. Microplastics in eviscerated flesh and excised organs of dried fish. Sci Rep 7:1-9.

Kolandhasamy P, Su L, Li J, Qu X, Jabeen K, Shi H, 2018. Adherence of microplastics to soft tissue of mussels: a novel way to uptake microplastics beyond ingestion. Sci Total Environ 610:635-40.

Li J, Green C, Reynolds A, Shi H, Rotchell JM, 2018. Microplastics in mussels sampled from coastal waters and supermarkets in the United Kingdom. Environ Pollut 241:35-44.

Li J, Lusher AL, Rotchell JM, Deudero S, Turra A, Bråte ILN, Shi H, 2019. Using mussel as a global bioindicator of coastal microplastic pollution. Environ Pollut 244:522-33.

Li J, Qu X, Su L, Zhang W, Yang D, Kolandhasamy P, Shi H, 2016. Microplastics in mussels along the coastal waters of China. Environ Pollut 214:177-84.

Lusher A, 2015. Microplastics in the marine environment: distribution, interactions and effects. In Marine anthropogenic litter (pp. 245-307). Springer, Cham.

Lusher AL, Welden NA, Sobral P, Cole M, 2017. Sampling, isolating and identifying microplastics ingested by fish and invertebrates. Anal Methods 9:1346-60.

Mathalon A, Hill P, 2014. Microplastic fibers in the intertidal ecosystem surrounding Halifax Harbor, Nova Scotia. Mar Pollut Bull 81:69-79.

Mercogliano R, Avio CG, Regoli F, Anastasio A, Colavita G, Santonicola S, 2020. Occurrence of Microplastics in Commercial Seafood under the Perspective of the Human Food Chain. A Review. J Agr Food Chem 68:5296301.

Mizraji R, Ahrendt C, Perez-Venegas D, Vargas J, Pulgar J, Aldana M, GalbánMalagón C, 2017. Is the feeding type related with the content of microplastics in intertidal fish gut?. Mar Pollut Bull 116:498-500.
Phuong NN, Poirier L, Pham QT, Lagarde F, Zalouk-Vergnoux A, 2018. Factors influencing the microplastic contamination of bivalves from the French Atlantic coast: location, season and/or mode of life?. Mar Pollut Bull 129:66474.

Qu X, Su L, Li H, Liang M, Shi H, 2018. Assessing the relationship between the abundance and properties of microplastics in water and in mussels. Sci Total Environ 621:679-86.

Renzi M, Guerranti C, Blašković A, 2018. Microplastic contents from maricultured and natural mussels. Mar Pollut Bull, 131:248-51.

Rummel CD, Löder MG, Fricke NF, Lang T, Griebeler EM, Janke M, Gerdts G, 2016. Plastic ingestion by pelagic and demersal fish from the North Sea and Baltic Sea. Mar Pollut Bull 102:134-41.

Santonicola S, García Ibarra V, Sendón R, Mercogliano R, Rodríguez-Bernaldo de Quirós A, 2017. Antimicrobial films based on chitosan and methylcellulose containing natamycin for active packaging applications. Coatings 7:177.

Setälä O, Norkko J, Lehtiniemi M, 2016. Feeding type affects microplastic ingestion in a coastal invertebrate community. Mar Pollut Bull 102:95-101.

Shim WJ, Hong SH, Eo S, 2018. Marine microplastics: abundance, distribution, and composition. In Microplastic Contamination in Aquatic Environments (pp. 1-26). Elsevier

Silva AB, Bastos AS, Justino CI, da Costa JP, Duarte AC, Rocha-Santos TA, 2018. Microplastics in the environment: Challenges in analytical chemistry-A review. Anal Chim Acta 1017:1-19.

Toussaint B, Raffael B, Angers-Loustau A, Gilliland D, Kestens V, Petrillo M, Van den Eede G, 2019. Review of micro-and nanoplastic contamination in the food chain. Food Addit Contam: Part A 36:639-73. 